\title{
Multi Objective Simulated Annealing Approach for Facility Layout Design
}

\author{
Safiye Turgay \\ Department of Industrial Engineering \\ Sakarya University, Esentepe Campus 54187, Serdivan, Turkey \\ E-mail: safiyeturgay@yahoo.com
}

(Received January 2, 2018; Accepted April 9, 2018)

\begin{abstract}
Facility layout design problem considers the departments' physcial layout design with area requirements in some restrictions such as material handling costs, remoteness and distance requests. Briefly, facility layout problem related to optimization of the layout costs and working conditions. This paper proposes a new multi objective simulated annealing algorithm for solving of the unequal area in layout design. Using of the different objective weights are generated with entropy approach and used in the alternative layout design. Multi objective function takes into the objective function and constraints. The suggested heuristic algorithm used the multi-objective parameters for initialization. Then prefered the entropy approach determines the weight of the objective functions. After the suggested improved simulated annealing approach applied to whole developed model. A multi-objective simulated annealing algorithm is implemented to increase the diversity and reduce the chance of getting layout conditions in local optima.
\end{abstract}

Keywords- Heuristics, Manufacturing, Multi objective simulated annealing algorithm, Unequal-area facilities, Entropy, Manufacturing facility layout design.

\section{Introduction}

Facility layout design problem is designing the layout of departments with some restrictions which are material handling costs, remoteness and distance requests. The multi objective Facility Layout Problem (FLP) close to optimization of the layout costs and the location of facilities (e.g., machines, departments) in a plant.

FLP is related to the location of facilities (machines, departments, etc.) and it is able to affect the system performance. Facility layout is associated to allocation of the activities to space such that a set of criteria (for example, area requirements) met of the some objectives are optimized. Suggested heuristic algorithm uses the entropy approach for determine the each objective function weight value. The main aim is minimize the materail handling cost and time with using efficient space in layout design. When the problem size increases, computational time and technique is getting hard for this reason FLPs are complex and NP-hard. Drira et al. offered a comprehensive FLP review, covering a wide spectrum of concepts ranging from its definitions, manufacturing systems, facility shapes, etc. to solution approaches, constraints, objectives, etc.

Heuristic methods are grouped into two groups the procedural and algorithmic themselves. The procedural approach such as the systematic layout planning realizes the facility layout design in three stages the analysis, search, and selection (Yang and Kuo, 2003). Also, the algorithmic approaches are divided in two classes, i.e., the constructed and improved the simulated annealing algorithm. The constructed algorithmic approaches as ALDEP (Seehof and Evans, 1967) and COROLAP (Lee and Moore, 1967) and the improved algorithmic approaches as CRAFT 
International Journal of Mathematical, Engineering and Management Sciences

Vol. 3, No. 4, 365-380, 2018

https://dx.doi.org/10.33889/IJMEMS.2018.3.4-026

(Armour and Buffa, 1963) and COFAD (Tompkins and Reed, 1976) are samples of these methods. Note that these methods have some limitations.

Many authors have used the metaheuristics approaches to obtain the near-optimal designs with simulated annealing approach to solve FLP (Al-Araidah et al., 2006; Khilwani et al., 2008; Singh and Singh, 2010; Chwif et al., 1998; McKendall et al., 2006; Ariafar and Ismail, 2009). Singh and Sharma (2008) and Şahin and Türkbey (2009) studied the simulated annealing approaches for the design of the facility layout design problems.

The proposed algorithm used the heuristic approach with initial solutions which are randomly generated and improved to yield the final suboptimal solution. This algorithm consists of three stages: the initial solution is constructed in the first stage, then the second stage used the entropped the weight values and the output of the second stage is improved in the third stage. The third stage of the algorithm is itself comprised of three different types of algorithms. These constituent algorithms are similar in that they both support unequal-area facilities, and their difference lies in the fact that one can accept any facility shape whereas the other only accepts rectangular facilities. Algorithms presented here are suitable for hierarchical layouts; therefore, it is recommended that space for facilities, operators and other requirements form workstations, workstations form departments and departments form the whole factory.

The remainder of paper structured as follows. In Section 2, multi objective facility layout problems reviewed. In Section 3, multi objective facility layout problem's mathematical model designed and recognized. The suggested multi objective simulated annealing algorithm represented in Section 4, the structural characteristics of the problem and the formulation approaches applied in Section 5. Finally, Section 6 provides conclusions and some research directions to be investigated in future research work.

\section{Literature Review}

FLP is so important for industrial engineers for this reason it applied in the wide area in real life and it is well designed and researched problem in academics. FLP is characterized as the problem of locating facilities in a limited area such that associated layout costs are minimized. Layout costs arise from various sources including material handling cost and time, and slack area. FLP aims to reduce material handling costs, work in process, lead times, utilize existing space more effectively and efficiently. In the beginning, the facilities are designed in several types of manufacturing systems then adopted the different areas such as construction sites, manufacturing industry and service industries and service sectors like supermarket, hospital. The problem of designing a physical layout of plant departments' main objective is minimizing the total material handling and layout costs which are time and slack area. Drira et al. 2007 reviewed the facility layout problems. Shayan and Chittilappilly (2004) defined the facility layout problem as an optimization problem that tries to make layouts more efficient by taking into account various interactions between facilities and material handling systems while designing layouts. Taghavi and Murat (2011) suggested the perturbation algorithm and sequencial location analysis insted of the integrated facility layout design and flow assignment problem with nonlinear mixed integer model. Saraswat et al. (2015) used the flow-distance parameters in framework for multi-objective design and Defresh and Hodiya (2017) suggested mathematical model for improving of the materail handling efficiency. Ahmadi et al. (2017) realized the literature survey for facility layout design problems. 
International Journal of Mathematical, Engineering and Management Sciences

Vol. 3, No. 4, 365-380, 2018

https://dx.doi.org/10.33889/IJMEMS.2018.3.4-026

Allahyari and Azab (2015) suggested the unequal area based bi-level facility layout problem mathematical model and heuritstic algorithm. Rossin classified the complexity measures of the facility layout problems. As defined in the literature, the objective of the layout design problem is the minimization of the material handling cost within a facility taking into consideration the following two sets of constraints: (a) departmental and floor area requirements and (b) departmental locational restrictions. Constraints set (a) ensures departments are located within the given perimeters of the plant, while constraints set (b) prevents departments from overlapping (Castillo and Sim, 2004; Chiang and Kouvelis, 1996; Heragu and Kusiak, 1991; Meller and Gau, 1996). Jankovits et al. (2011) developed mathematical model and the convex optimization framework for unequal-areas facility layout problem. Defersha and Hodiya (2017) modeled the integrated distributed layout design.

Several solution methods for FLP are developed in the literature; these can be categorized as follows: (1) exact optimization approaches, (2) heuristics, and (3) metaheuristics. The authors find the taxonomy provided by Drira et al. (2007) to be quite comprehensive; few issues are noted, though. Firstly, the authors in their figure one summarizing their classification are mistakenly labeling the first category as "Manufacturing System".

The proposed algorithm of this paper is classified as a heuristic improvement algorithm since initial solutions are randomly generated and improved to yield the final suboptimal solution. This algorithm consists of two stages: the initial solution is constructed in the first stage and the output of the first stage is improved in the second stage. The second stage of the algorithm is itself comprised of two different types of algorithms. These constituent algorithms are similar in that they both support unequal-area facilities, and their difference lies in the fact that one can accept any facility shape whereas the other only accepts rectangular facilities. Algorithms presented here are suitable for hierarchical layouts; therefore, it is recommended that space for facilities, operators and other requirements form workstations, workstations form departments and departments form the whole factory. These algorithms are tested for various runs of the algorithm with different parameter settings to acquire their running time in each case. A user interface is designed to monitor performance of the algorithm via dynamic modification of parameters while algorithms are running which is called FLCD (Facility Layout Collision Detection).

Singh and Singh (2010) suggested the Multi-Objective Facility Layout Problem (MOFLP) model which generates a different layout by varying objectives weights and they demonstrated the objective weights important role in the layout design of MOFLP. In practice, it is selected randomly by the layout designer based on his/her past experience that restricts the layout designing process completely designer dependent and thus the layout varies from designer to designer. This study suggested the entreopy approach for the objective weights.

A comprehensive mathematical model for pure continuous detailed MOFLP is presented. The developed model can be used in manufacturing systems, where different carriers with different capacities are used to transport parts among facilities/department.

\section{Facility Layout Design}

FLP is an important problem which is defined as the problem of locating facilities in a limited area and resources. These are NP-complete that means the amount of computation increases exponentially with problem size. In this study, unequal-area constraints are considered in the multi-facility layout design mathematical model that is applied on the suggested improved 
International Journal of Mathematical, Engineering and Management Sciences

Vol. 3, No. 4, 365-380, 2018

https://dx.doi.org/10.33889/IJMEMS.2018.3.4-026

simulated annealing approach. Layout costs arise from various sources including material handling, time, and slack area. The multi-objective facility layout design steps are given below. In this section the multi-facility layout desig in model functions reviewed which based on the objective functions, constraints and decision variables.

A multi-objective facility layout design steps:

STEP 1: Data collection.

STEP 2: Determine of the space requirements of the current plan and required plan.

STEP 3: Consider the relationship diagram and space relationship diagram.

STEP 4: Modeling of the objective function.

STEP 5: Determine and modeling of the constraints.

STEP 6: Analysis of the flow analysis-quantitative analysis and space availability.

STEP 7: Analysis of the objective function with constraints using of the simulated annealing approach.

STEP 8: Determine of the optimum facility layout plan.

The model also considers the capacity changes along time, as well as changes in the transportation costs between facilities. This multi-objective model is designed considering the total material handling costs, the reconfiguration costs, the remoteness function with adjacaceny of the departments (due to the importance of locating high affinity departments at the same facility), and a new objective designated as unsuitability. The unsuitability between departments and locations has a special importance for layout reconfigurations, since it somehow measures the adequacy of the features of each location to the requirements of each department.

\section{Mathematical Model}

In this section, multi objectives facility layout functions are presented in mathematical model. Contraints express to the system restrictions with considering of the resources. After the optimization process system considers the satisfaction degree, efficieny and maksimum profit. This study considers the unequal size.

The facility layout problem considered the arranging of $\mathrm{n}$ unequal-area facilities in sizes $w_{i} \times l_{i}$, where $w_{i}$ and $l_{i}$ are the given width and the length of each facility, respectively, $i=1, \ldots, n$, within a given total space which can be bounded to the length or width of site area in a way to minimize the total material handling cost, reconfiguration cost, remoteness function, using of the area, unsuitability between departments (Eq. 1). The material handling cost between facility $i$ and $j$ is given by $c_{i j} f_{i j} d_{i j}$ where $c_{i j}$ is the cost of one unit of flow between $i$ and $j, f_{i j}$ is the amount of flow between $i$ and $j$, and $\mathrm{d}_{\mathrm{ij}}$ is the distance between $i$ and $j$.

The MFLP allocates departments at different facilities, taking into consideration transportation costs and operational constraints between facilities.

The problem is formulated under the following assumptions:

(i) Facilities are unequal size.

(ii) Facilities must be located within a given area.

(iii) Facilities must not overlap with each other.

(iv) The demand is known. 
International Journal of Mathematical, Engineering and Management Sciences

Vol. 3, No. 4, 365-380, 2018

https://dx.doi.org/10.33889/IJMEMS.2018.3.4-026

The following practical considerations were taken into account when formulating the developed model; these were ignored by Heragu and Kusiak (1991).

\section{Indices}

$Z \quad$ objective function value for Multi Objective Facility Layout Design

$p \quad$ number of objectives

$F \quad$ number of facilities

$N \quad$ number of characteristics to evaluate the suitability between departments and locations

$n \quad$ the number of departments in the layout, the area

\section{Parameters}

$x_{i j} \quad$ the 0,1 varaible for locating departments $i$ and location $j$

$f_{i j} \quad$ work flow from facility $i$ to facility $k$

$c_{i j} \quad$ the unit cost (the cost to move one unit load one distance)

$d_{i j} \quad$ distance from location $j$ to location $l$

$l_{i j} \quad$ the contact premier length between departments $i$ and $j$

$r_{i j} \quad$ the remoteness rating

$\mathrm{Cr}$ total reconfiguration cost

$L_{i j} \quad$ length of the two dimensional rectangle

$W_{i j} \quad$ width of the two dimensional rectangle

$c r_{i} \quad$ cost of shifting department $i$

$\alpha \quad$ objective weight for the materail handling cost

$\beta \quad$ objective weight for the remoteness function

$\theta \quad$ objective weight for using of the area

$\delta \quad$ objective weight for reconfiguration cost

\section{Decision Variables}

$x_{i(f, l) t} \quad 1, \quad$ if department $i$ is placed at position $l$, in facility $f$, in period $t$;

0, otherwise.

$D_{j} \quad$ Demand quantity for material $j$;

$U_{j o i} \quad 1, \quad$ if operation o of material $j$ can be done by facility $i$;

0 , otherwise.

The objective function is:

$\operatorname{Min} \mathrm{Z}=f(x)=\alpha \sum_{\mathrm{i}} \sum_{\mathrm{j}}\left(f_{i j} c_{i j}\right) \mathrm{x}_{i j} d_{i j}+\beta \sum_{\mathrm{i}} \sum_{\mathrm{j}}\left(r_{i j} l_{i j}\right) \mathrm{x}_{i j}+\theta$

\section{(i) Material Handling Cost}

The first objective function is material handling cost which is applied to unequal area in FLP.

$\alpha \sum_{\mathrm{i}} \sum_{\mathrm{j}}\left(f_{i j} c_{i j}\right) \mathrm{x}_{i j} d_{i j}$

\section{(ii) Remoteness Function}

Minimization of the remoteness function uses the $r_{i j}$ remoteness rating variable and $l_{i j}$.

$\beta \sum_{\mathrm{i}} \sum_{\mathrm{j}}\left(r_{i j} l_{i j}\right) \mathrm{x}_{i j}$ 
International Journal of Mathematical, Engineering and Management Sciences

Vol. 3, No. 4, 365-380, 2018

https://dx.doi.org/10.33889/IJMEMS.2018.3.4-026

(iii) Using of the Area

This function evaluates the departments located in the facility properly.

$\theta \sum_{\mathrm{i}} \sum_{\mathrm{j}}\left(\frac{\min \left\{L_{i j}, W_{i j}\right.}{\max \left\{L_{i j}, W_{i j}\right.}\right) x_{i j}$

(iv) Reconfiguration Cost

The model considers the total costs of reconfiguring a layout with below equation.

$\delta \sum_{\mathrm{i}} \sum_{\mathrm{j}}\left(C r_{i j} x_{i j}\right)$

Model constraints are:

$\alpha+\beta+\theta+\delta+\varphi=1$

(v) Budget Constraints

$\sum_{\mathrm{i}} \sum_{\mathrm{j}}\left(f_{i j} c_{i j}\right) \mathrm{x}_{i j} d_{i j}+\sum_{\mathrm{i}} \sum_{\mathrm{j}}\left(C r_{i j} x_{i j}\right) \leq \max ^{*} d_{i j} *_{\text {sales price }}$

(vi) Assignment Constraints

$\sum_{\mathrm{i}} \sum_{\mathrm{j}} x_{i j}=1, \quad \forall \mathrm{i} \in \mathrm{I}$

(vii) Precedence Constraints

$\sum_{\mathrm{i}} \sum_{\mathrm{j}} j x_{h j} \leq \sum_{\mathrm{i}} \sum_{\mathrm{j}} j x_{i j}, \quad \forall \mathrm{i} \in \mathrm{I}, \mathrm{h}, \mathrm{i}, \mathrm{j} \in \mathrm{I}$

The assignment of tasks to workers of multi-manned workstations must follow the precedence constraints of the problem. Task $i$ can be assigned to worker $k$ of multi-manned workstation $j$, when all of its predecessors like $h$ are assigned to prior workstations. The precedence constraint (Eq. 9) ensures that all such precedence relationships for all models are satisfied.

\section{(viii) Area Constraints}

$$
\sum_{i \Rightarrow m} a_{i} \leq A_{m}
$$

\section{(ix) Non-Negativity Constraints}

All of the variables are nonnegative. The objective function sums up the cost terms which relates to the activities and location pairs. The movement cost, $c_{i k j} h$, is added to the total cost only if activities $i$ and $j$ are indeed assigned to locations $k$ and $h$ and $x_{i k}$ and $x_{j h}$ are both positive. The first set of constraints ensures that each location will have exactly one activity assigned to it, while the second guarantees that each activity is assigned to exactly one location. The upshot of both sets of constraints is that each activity is assigned the exclusive use of one location, which is what is necessary for the solution to be valid. 
International Journal of Mathematical, Engineering and Management Sciences

Vol. 3, No. 4, 365-380, 2018

https://dx.doi.org/10.33889/IJMEMS.2018.3.4-026

\section{Improved Simulated Annealing Approach}

Simulated annealing is a combinatorial optimization algorithm. Kirkpatrick et al. (1983) firstly introduced and Eglese (1990) used and applied to with local search algorithm in operations research. The algorithm obtained and simulated the cooling of a mass of vibrating atoms from a high temperature $T$. According to Ligget (2000) the probability of acceptance ( $p$ ) of the replace of a pair of activities equals one when the replace offers a better value of the objective function. When the cost change is positive (i.e., increases the cost), the probability of acceptance $p$ is a function of the diversity of the values in objective function for the current solution and the new solution $(\Delta)$, and an additional control parameter, $T$ (which represents temperature in the actual annealing process):

$p=(\exp (-\Delta / T))$

In general, the lower temperature $T$ provides the little of the chances for the acceptance of a new solution. During execution of the algorithm, the temperature of the system, $T$, is lowered in steps. When the $T$ reaches to zero, the algorithm terminates and obtained the optimum value. The suggested below algorithm adapted from Rardin (2000).

Step 0: Initialization: Choose randomly any starting feasible solution $x^{(0)}$, an iteration limit $t_{\max }$, and a relatively large initial temperature $q>0$. Then set incumbent solution $\hat{x} \leftarrow x^{(0)}$ and solution index $t \leftarrow 0 . x$ represents the each nodes (facility options).

Step 1: Stopping: If no move $\Delta x$ in move set $\mathrm{M}$ leads to a feasible neighbor of current solution $x^{(t)}$, or if $t=t_{\max }$, then stop. Incumbent solution $\hat{x}$ is an approximate optimum.

Step 2: Provisional Move: Randomly choose a feasible move $\Delta x \in M$ as aprovisional $\Delta x^{(t+1)}$, and compute the (possibly negative) net objective function improvement $\Delta$ obj for moving from $x^{(t)}$ to $\left(x^{(t)}+\Delta x^{(t+1)}\right)$.

If there are no inbound arcs at node $p$, set $v[p] \leftarrow \infty$. Otherwise, compute

$$
x^{(t)} \leftarrow \min \left\{x^{(t)}+C i, p:(i, p) \text { exists }\right\} \text {. Then return to Step } 0 .
$$

Step 3: Acceptance: If $\Delta x^{(t+1)}$ improves, or with probability $e^{\Delta o b j / q}$ if $\Delta o b j \leq 0$, accept $\Delta x^{(t+1)}$ and update.

$$
x^{(t+1)} \leftarrow x^{(t)}+\Delta x^{(t+1)}
$$

Otherwise, return to Step 2.

Step 4: Incumbent Solution: If the objective function value of $x^{(t+1)}$ is superior to that of incumbent solution $\hat{x}$, replace $\hat{x} \leftarrow x^{(t+1)}$.

Step 5: Temperature Reduction: If a sufficient number of iterations have passed since the last temperature change, reduce temperature $q$.

Step 6: Increment: Increment $t \leftarrow t+1$, and return to Step1. 
International Journal of Mathematical, Engineering and Management Sciences

Vol. 3, No. 4, 365-380, 2018

https://dx.doi.org/10.33889/IJMEMS.2018.3.4-026

\section{Application}

Singh and Singh (2010) proposed three stage heuristic approach for solving MOFLP. Our suggested heuristic approach includes the three main steps which are: (a) data matrix of each objective is normalized; (b) entropy based approach used the computation of the objective weight; and (c) MOFLP is solved with linear programming and multi-objective simulated annealing approach for $n=9$. An improved simulated annealing for multi objective facility layout problem.

In this section, facility location and among of the relations are considered. The related factors are given in below. Fig.1 represents the each facility layout situations. These parameters are used in the our facility layout design with evaluation criteria.

Once objective weights have been calculated, the MOFLP is solved as single objective FLP considering the original objective matrixes. For this purpose, modified SA algorithm is used. An initial feasible solution $A$ is generated. For obtaining an initial solution $A$ the facilities are allotted to locations in a sequential manner such that facility 1 is in location 1 , facility 2 is in location 2 and so on. The composite relationship and the distance matrix for the initial configuration form considered as the other inputs to the program. From the above the combined objective function value $(Z)$ is computed using Eq. (1).

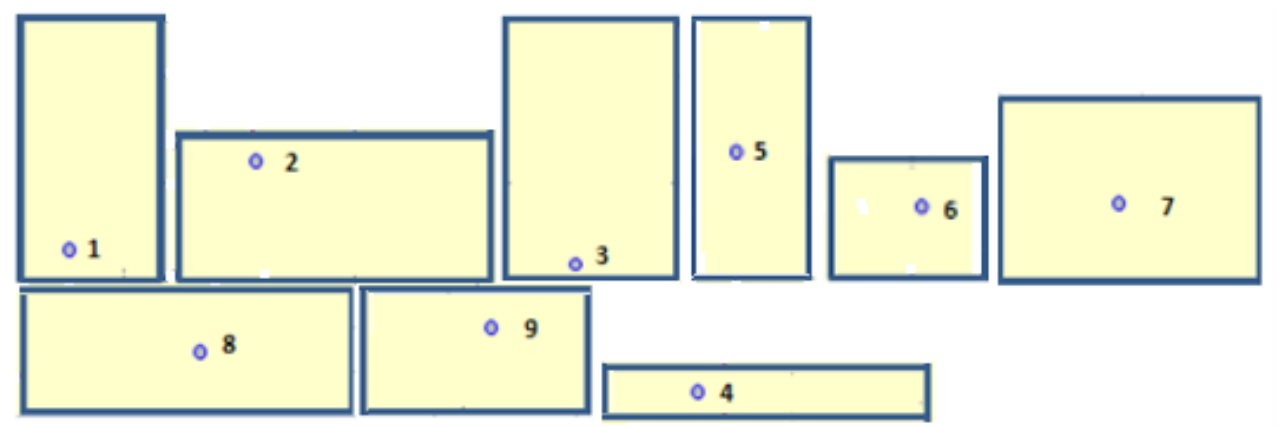

Fig. 1. Facility layouts

Table 1. Facilities and location coordinations

\begin{tabular}{|c|c|c|}
\hline Facility No & X & Y \\
\hline F1 & 53,1075 & 7,7266 \\
\hline F2 & 87,6740 & 72,6670 \\
\hline F3 & 74,43245 & 5,153024 \\
\hline F4 & 86,19077 & 79,72915 \\
\hline F5 & 20,40916 & 40,73364 \\
\hline F6 & 33,91671 & 48,14801 \\
\hline F7 & 55,36254 & 90,24361 \\
\hline F8 & 97,27642 & 97,39993 \\
\hline F9 & 64,61363 & 66,46982 \\
\hline
\end{tabular}


International Journal of Mathematical, Engineering and Management Sciences

Vol. 3, No. 4, 365-380, 2018

https://dx.doi.org/10.33889/IJMEMS.2018.3.4-026

Table 1 represents the facilities and location coordinations. Table 2 represents the distance matrix of the facilities. Euclidean distance parameters used to find among of the facilities distance value. Fig. 2 shows the sample facility layout design for F1-F5-F6-F9-F7-F8-F4-F2-F3.

Table 2. Distance matrix of the facilities

\begin{tabular}{|c|c|c|c|c|c|c|c|c|c|}
\hline $\begin{array}{c}\text { Facility } \\
\text { No }\end{array}$ & F1 & F2 & F3 & F4 & F5 & F6 & F7 & F8 & F9 \\
\hline F1 & & 73,567 & 21,47973 & 79,23931 & 46,46118 & 44,74565 & 82,54779 & 99,96098 & 59,85946 \\
\hline F2 & & & 68,80029 & 7,216212 & 74,46009 & 59,08496 & 36,78273 & 26,53153 & 23,8786 \\
\hline F3 & & & & 75,4974 & 64,68768 & 59,07702 & 87,20132 & 95,03335 & 62,09798 \\
\hline F4 & & & & 76,47137 & 61,07328 & 32,57197 & 20,8602 & 25,32553 \\
\hline F5 & & & & & & 15,40866 & 60,60509 & 95,49683 & 51,15063 \\
\hline F6 & & & & & & & 47,24366 & 80,25088 & 35,74899 \\
\hline F7 & & & & & & & & 42,52042 & 25,51031 \\
\hline F8 & & & & & & & & & 44,98365 \\
\hline F9 & & & & & & & & & \\
\hline
\end{tabular}

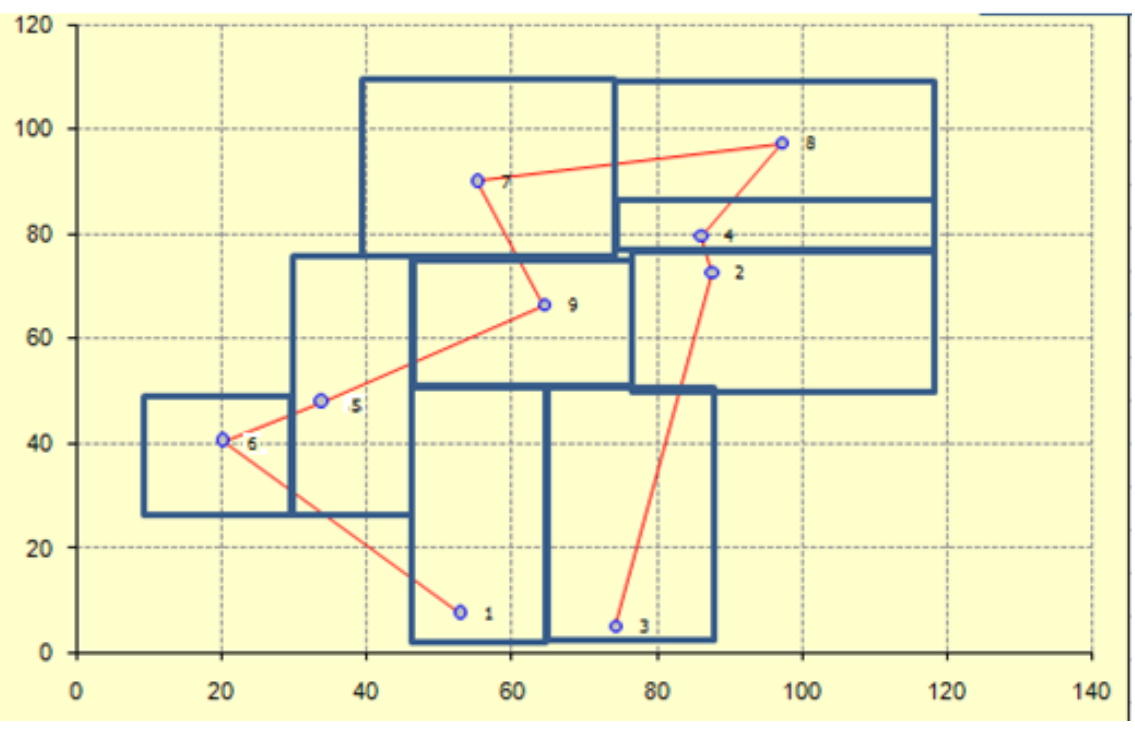

Fig. 2. Sample facility layout design

The performance evaluation considers the $n=9$ unequal facility layout heuristic problem size. The improves SA heuristic problem strucure uses the whole multi objective function elements. Which are material handling cost, remoteness fuction, using of the area, reconfiguration cost and suitably between departments and locations. In the litearaure Rosenblatt (1986), Chen and Sha (2005) consider the work flow and closeness rating objectives. Fortenberry and Cox (1985) analyzed the facility layout problems with multi criteria decision making approach. Also Torkul et al. (2013) used the fuzzy grey relation aprroach to analysis of the facility layout design problem parameters. Singh and Singh (2010) demonstrated the effectiveness of proposed modified SA. Our suggetsed algorithm includes the below steps: 
International Journal of Mathematical, Engineering and Management Sciences

Vol. 3, No. 4, 365-380, 2018

https://dx.doi.org/10.33889/IJMEMS.2018.3.4-026

\section{Step 1: Matrix Normalization}

This stage normalized the objective function's parameters which are the material handling cost, remoteness fuction, using of the area, reconfiguration cost and suitably between departments and locations matrix.

\section{Step 2: Objective Weight Computation}

In the second stage, relative weight of each objective is determined with using of the entropy. Material handling cost, remoteness fuction, using of the area, reconfiguration cost and suitably between departments and locations matrix. The weight function values are obtained from Shannon's entropy rule which are $\alpha=0.4871$ (weight for material handling cost, $\beta=0.1207$ (weight for remoteness function), $\theta=0.0946$ (weight for using of the area), $\delta=0.0858$ (weight for reconfiguration cost) and $\varphi=0.1285$ (weight for suitably between departments and location matrix). The Entropy is

$$
\tilde{E}_{j}=-k \sum_{i=1}^{n} e_{i j} \operatorname{In} e_{i j} \cdot=-\frac{1}{\operatorname{Inm}} \sum_{i-1}^{n} e_{i j} \operatorname{In} e_{i j}
$$

In the final step, MOFLP is solved with using proposed modified SA in this paper. The objective function main parameters are listed in Table 3 and calculated parameters are expressed in Table 5. Also Table 4 shows the remoteness function value among the facilities. Table 6 represents the using of the area. Reconfiguration costs are given in Table 7. Suitable situations among the facilities ( 0 -represents the negative situation, 1 represents the positive situation) in Table 8 . The objective values obtained and given in the Table 9.

Table 3. Cost coefficients

\begin{tabular}{|c|c|c|c|c|c|c|c|c|c|}
\hline & F1 & F2 & F3 & F4 & F5 & F6 & F7 & F8 & F9 \\
\hline F1 & & 0,05 & 0,1 & 0,1 & 0,11 & 0,15 & 0,14 & 0,15 & 0,2 \\
\hline F2 & & & 0,2 & 0,15 & 0,1 & 0,1 & 0,15 & 0,1 & 0,2 \\
\hline F3 & & & & 0,16 & 0,1 & 0,16 & 0,22 & 0,18 & 0,18 \\
\hline F4 & & & & & 0,22 & 0,18 & 0,25 & 0,15 & 0,2 \\
\hline F5 & & & & & & 0,2 & 0,15 & 0,16 & 0,12 \\
\hline F6 & & & & & & & 0,12 & 0,15 & 0,1 \\
\hline F7 & & & & & & & & 0,1 & 0,2 \\
\hline F8 & & & & & & & & & 0,2 \\
\hline F9 & & & & & & & & & \\
\hline
\end{tabular}

Table 4. Remoteness function value among the facilities

\begin{tabular}{|l|l|l|l|l|l|l|l|l|l|}
\hline & F1 & F2 & F3 & F4 & F5 & F6 & F7 & F8 & F9 \\
\hline F1 & & 0,1 & 0,2 & 0,3 & 0,1 & 0,2 & 0,3 & 0,2 & 0,3 \\
\hline F2 & & & 0,3 & 0,2 & 0,2 & 0,3 & 0,4 & 0,3 & 0,2 \\
\hline F3 & & & & 0,2 & 0,3 & 0,3 & 0,2 & 0,2 & 0,1 \\
\hline F4 & & & & & 0,2 & 0,1 & 0,3 & 0,4 & 0,4 \\
\hline F5 & & & & & & 0,4 & 0,3 & 0,2 & 0,2 \\
\hline F6 & & & & & & & 0,3 & 0,4 & 0,2 \\
\hline F7 & & & & & & & & 0,2 & 0,3 \\
\hline F8 & & & & & & & & & 0,3 \\
\hline F9 & & & & & & & & & \\
\hline
\end{tabular}


International Journal of Mathematical, Engineering and Management Sciences

Vol. 3, No. 4, 365-380, 2018

https://dx.doi.org/10.33889/IJMEMS.2018.3.4-026

Table 5. Calculated of the objective function parameters

\begin{tabular}{|c|c|c|c|c|c|c|c|c|c|c|c|c|}
\hline Alternatives & 1 & 2 & 3 & 4 & 5 & 6 & 7 & 8 & 9 & Material Handling Cost & Remoteness Function Value & Cost Coefficients \\
\hline 1 & 7 & 6 & 8 & 9 & 1 & 2 & 3 & 4 & 5 & 526,673703 & 2,1 & 1,3 \\
\hline 2 & 8 & 7 & 9 & 1 & 2 & 3 & 4 & 5 & 6 & 437,634894 & 2 & 1,33 \\
\hline 3 & 7 & 6 & 5 & 8 & 9 & 1 & 2 & 3 & 4 & 480,856938 & 2,1 & 1,29 \\
\hline 4 & 8 & 7 & 6 & 9 & 1 & 2 & 3 & 4 & 5 & 479,708578 & 1,8 & 1,15 \\
\hline 5 & 9 & 8 & 7 & 1 & 2 & 3 & 4 & 5 & 6 & 479,796568 & 2 & 1,27 \\
\hline 6 & 7 & 5 & 6 & 4 & 8 & 9 & 1 & 2 & 3 & 405,157625 & 1,9 & 1,13 \\
\hline 7 & 1 & 8 & 9 & 7 & 2 & 3 & 4 & 5 & 6 & 443,415377 & 2 & 1,28 \\
\hline 8 & 7 & 3 & 4 & 5 & 6 & 2 & 8 & 9 & 1 & 445,038338 & 2,2 & 1,4 \\
\hline 9 & 7 & 2 & 3 & 4 & 5 & 6 & 1 & 8 & 9 & 462,650716 & 2,2 & 1,43 \\
\hline 10 & 4 & 8 & 9 & 1 & 2 & 3 & 7 & 5 & 6 & 431,285662 & 2,3 & 1,37 \\
\hline 11 & 6 & 9 & 1 & 2 & 3 & 4 & 5 & 8 & 7 & 527,961744 & 1,7 & 1,19 \\
\hline 12 & 7 & 1 & 2 & 3 & 4 & 5 & 6 & 9 & 8 & 473,025138 & 2 & 1,27 \\
\hline 13 & 6 & 8 & 9 & 1 & 2 & 3 & 4 & 5 & 7 & 540,03513 & 2,1 & 1,33 \\
\hline 14 & 7 & 9 & 1 & 2 & 3 & 4 & 5 & 6 & 8 & 490,611302 & 2 & 1,39 \\
\hline 15 & 5 & 7 & 6 & 8 & 9 & 1 & 2 & 3 & 4 & 510,807425 & 2,2 & 1,23 \\
\hline 16 & 6 & 8 & 7 & 9 & 1 & 2 & 3 & 4 & 5 & 502,47712 & 2 & 1,28 \\
\hline 17 & 7 & 9 & 8 & 1 & 2 & 3 & 4 & 5 & 6 & 480,199643 & 2 & 1,38 \\
\hline$\ldots$ & $\ldots$ & $\ldots$ & $\ldots$ & $\ldots$ & $\ldots$ & $\ldots$ & $\ldots$ & $\ldots$ & $\ldots$ & 498,734039 & 1,8 & 1,09 \\
\hline 66 & 7 & 8 & 9 & 1 & 2 & 3 & 6 & 5 & 4 & 440,687863 & 2,1 & 1,33 \\
\hline 67 & 9 & 1 & 2 & 3 & 4 & 5 & 8 & 7 & 6 & 449,855051 & 1,9 & 1,18 \\
\hline 68 & 9 & 1 & 2 & 3 & 4 & 5 & 6 & 8 & 7 & 492,37547 & 2,1 & 1,28 \\
\hline
\end{tabular}

Table 6. Using of the area

\begin{tabular}{|c|c|}
\hline Facilities & Using of area(\%) \\
\hline F1 & $80 \%$ \\
\hline F2 & $90 \%$ \\
\hline F3 & $60 \%$ \\
\hline F4 & $88 \%$ \\
\hline F5 & $95 \%$ \\
\hline F6 & $90 \%$ \\
\hline F7 & $85 \%$ \\
\hline F8 & $96 \%$ \\
\hline F9 & $99 \%$ \\
\hline
\end{tabular}


International Journal of Mathematical, Engineering and Management Sciences

Vol. 3, No. 4, 365-380, 2018

https://dx.doi.org/10.33889/IJMEMS.2018.3.4-026

Table 7. Reconfiguration cost

\begin{tabular}{|c|c|}
\hline Facilities & Reconfiguration Cost \\
\hline F1 & 88000 \\
\hline F2 & 92000 \\
\hline F3 & 50000 \\
\hline F4 & 25000 \\
\hline F5 & 45000 \\
\hline F6 & 20000 \\
\hline F7 & 15000 \\
\hline F8 & 18000 \\
\hline F9 & 20000 \\
\hline
\end{tabular}

Table 8. Suitable situations among the facilities (0-represents the negative situation, 1 represents the positive situation)

\begin{tabular}{|c|c|c|c|c|c|c|c|c|c|}
\hline & F1 & F2 & F3 & F4 & F5 & F6 & F7 & F8 & F9 \\
\hline F1 & - & 1 & 0 & 0 & 1 & 1 & 0 & 1 & 1 \\
\hline F2 & & - & 1 & 0 & 1 & 1 & 0 & 0 & 1 \\
\hline F3 & & & - & 1 & 0 & 0 & 1 & 0 & 0 \\
\hline F4 & & & & - & 1 & 1 & 0 & 1 & 1 \\
\hline F5 & & & & & - & 1 & 0 & 1 & 0 \\
\hline F6 & & & & & & - & 0 & 1 & 0 \\
\hline F7 & & & & & & & - & 0 & 1 \\
\hline F8 & & & & & & & & - & 1 \\
\hline F9 & & & & & & & & & - \\
\hline
\end{tabular}

MOFLP of size $n=9$ is solved using proposed three step approach in this paper and objective weights, objective function value and feasible layout plans are given in Table 9. 
International Journal of Mathematical, Engineering and Management Sciences

Vol. 3, No. 4, 365-380, 2018

https://dx.doi.org/10.33889/IJMEMS.2018.3.4-026

Table 9. Computational results

\begin{tabular}{|c|c|c|c|c|c|c|c|c|c|c|c|c|c|c|c|c|c|}
\hline 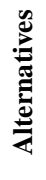 & F1 & F2 & F3 & F4 & F5 & F6 & F7 & F8 & F9 & 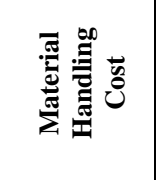 & 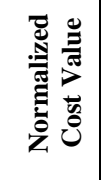 & 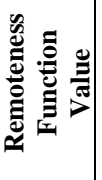 & ن & 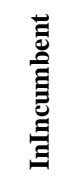 & वे & $\begin{array}{l}\overline{\mathscr{e}} \\
\dot{0} \\
\square \\
\square\end{array}$ & $\begin{array}{l}Z \\
0 \\
0 \\
0 \\
0 \\
0 \\
0\end{array}$ \\
\hline 1 & 7 & 6 & 8 & 9 & 1 & 2 & 3 & 4 & 5 & 526,673703 & 3,4178 & 2,1 & 1,3 & 2,27 & 5 & 0,22 & REJECT \\
\hline 2 & 8 & 7 & 9 & 1 & 2 & 3 & 4 & 5 & 6 & 437,634894 & 2,84 & 2 & 1,33 & 2,06 & 5 & $-0,11$ & ACCEPT \\
\hline 3 & 7 & 6 & 5 & 8 & 9 & 1 & 2 & 3 & 4 & 480,856938 & 3,1205 & 2,1 & 1,29 & 2,17 & 5 & 0,15 & REJECT \\
\hline 4 & 8 & 7 & 6 & 9 & 1 & 2 & 3 & 4 & 5 & 479,708578 & 3,1131 & 1,8 & 1,15 & 2,02 & 5 & $-0,11$ & REJECT \\
\hline 5 & 9 & 8 & 7 & 1 & 2 & 3 & 4 & 5 & 6 & 479,796568 & 3,1136 & 2 & 1,27 & 2,13 & 5 & 0,24 & REJECT \\
\hline 6 & 7 & 5 & 6 & 4 & 8 & 9 & 1 & 2 & 3 & 405,157625 & 2,6293 & 1,9 & 1,13 & 1,89 & 5 & $-0,17$ & ACCEPT \\
\hline 7 & 1 & 8 & 9 & 7 & 2 & 3 & 4 & 5 & 6 & 443,415377 & 2,8775 & 2 & 1,28 & 2,05 & 5 & $-0,11$ & ACCEPT \\
\hline 8 & 7 & 3 & 4 & 5 & 6 & 2 & 8 & 9 & 1 & 445,038338 & 2,8881 & 2,2 & 1,4 & 2,16 & 5 & $-0,05$ & REJECT \\
\hline 9 & 7 & 2 & 3 & 4 & 5 & 6 & 1 & 8 & 9 & 462,650716 & 3,0024 & 2,2 & 1,43 & 2,21 & 5 & 0,05 & REJECT \\
\hline 10 & 4 & 8 & 9 & 1 & 2 & 3 & 7 & 5 & 6 & 431,285662 & 2,7988 & 2,3 & 1,37 & 2,16 & 5 & 0,05 & ACCEPT \\
\hline 11 & 6 & 9 & 1 & 2 & 3 & 4 & 5 & 8 & 7 & 527,961744 & 3,4262 & 1,7 & 1,19 & 2,11 & 5 & $-0,01$ & REJECT \\
\hline 12 & 7 & 1 & 2 & 3 & 4 & 5 & 6 & 9 & 8 & 473,025138 & 3,0697 & 2 & 1,27 & 2,11 & 5 & $-0,2$ & REJECT \\
\hline 13 & 6 & 8 & 9 & 1 & 2 & 3 & 4 & 5 & 7 & 540,03513 & 3,5046 & 2,1 & 1,33 & 2,31 & 5 & 0,12 & REJECT \\
\hline 14 & 7 & 9 & 1 & 2 & 3 & 4 & 5 & 6 & 8 & 490,611302 & 3,1838 & 2 & 1,39 & 2,19 & 5 & $-0,06$ & REJECT \\
\hline 15 & 5 & 7 & 6 & 8 & 9 & 1 & 2 & 3 & 4 & 510,807425 & 3,3149 & 2,2 & 1,23 & 2,25 & 5 & 0,07 & REJECT \\
\hline 16 & 6 & 8 & 7 & 9 & 1 & 2 & 3 & 4 & 5 & 502,47712 & 3,2608 & 2 & 1,28 & 2,18 & 5 & 0,01 & REJECT \\
\hline 17 & 7 & 9 & 8 & 1 & 2 & 3 & 4 & 5 & 6 & 480,199643 & 3,1163 & 2 & 1,38 & 2,17 & 5 & 0,12 & REJECT \\
\hline 18 & 5 & 8 & 7 & 6 & 9 & 1 & 2 & 3 & 4 & 498,734039 & 3,2365 & 1,8 & 1,09 & 2,04 & 5 & $-0,03$ & REJECT \\
\hline 19 & 6 & 9 & 8 & 7 & 1 & 2 & 3 & 4 & 5 & 500,136899 & 3,2456 & 1,8 & 1,17 & 2,07 & 5 & $-0,14$ & REJECT \\
\hline 20 & 7 & 1 & 9 & 8 & 2 & 3 & 4 & 5 & 6 & 450,100136 & 2,9209 & 2,3 & 1,42 & 2,21 & 5 & 0,15 & REJECT \\
\hline 21 & 3 & 7 & 5 & 6 & 4 & 8 & 9 & 1 & 2 & 423,558651 & 2,7487 & 2,1 & 1,35 & 2,07 & 5 & $-0,09$ & REJECT \\
\hline 22 & 6 & 1 & 8 & 9 & 7 & 2 & 3 & 4 & 5 & 482,991046 & 3,1344 & 2 & 1,33 & 2,15 & 5 & $-0,08$ & REJECT \\
\hline 23 & 7 & 2 & 9 & 1 & 8 & 3 & 4 & 5 & 6 & 482,892537 & 3,1337 & 2,1 & 1,46 & 2,23 & 5 & 0 & REJECT \\
\hline 24 & 2 & 7 & 4 & 5 & 6 & 3 & 8 & 9 & 1 & 420,188209 & 2,7268 & 2,4 & 1,56 & 2,23 & 5 & 0,21 & ACCEPT \\
\hline 25 & 7 & 3 & 9 & 1 & 2 & 8 & 4 & 5 & 6 & 421,997507 & 2,7386 & 2 & 1,32 & 2,02 & 5 & $-0,2$ & ACCEPT \\
\hline 26 & 7 & 4 & 9 & 1 & 2 & 3 & 8 & 5 & 6 & 466,063084 & 3,0245 & 2,2 & 1,44 & 2,22 & 5 & 0,07 & REJECT \\
\hline 27 & 6 & 4 & 8 & 9 & 1 & 2 & 3 & 7 & 5 & 476,950285 & 3,0952 & 2 & 1,35 & 2,15 & 5 & $-0,04$ & REJECT \\
\hline 28 & 7 & 5 & 9 & 1 & 2 & 3 & 4 & 8 & 6 & 490,590945 & 3,1837 & 2,2 & 1,18 & 2,19 & 5 & 0,06 & REJECT \\
\hline 29 & 8 & 6 & 1 & 2 & 3 & 4 & 5 & 9 & 7 & 495,993519 & 3,2187 & 1,9 & 1,25 & 2,12 & 5 & $-0,05$ & REJECT \\
\hline 30 & 9 & 7 & 2 & 3 & 4 & 5 & 6 & 1 & 8 & 443,177374 & 2,876 & 2,2 & 1,43 & 2,17 & 5 & 0,01 & ACCEPT \\
\hline 31 & 7 & 6 & 9 & 1 & 2 & 3 & 4 & 5 & 8 & 532,684986 & 3,4569 & 1,8 & 1,21 & 2,16 & 5 & 0,11 & REJECT \\
\hline 32 & 8 & 7 & 1 & 2 & 3 & 4 & 5 & 6 & 9 & 470,561908 & 3,0537 & 1,9 & 1,17 & 2,04 & 5 & $-0,23$ & REJECT \\
\hline 33 & 4 & 5 & 7 & 6 & 8 & 9 & 1 & 2 & 3 & 511,781395 & 3,3212 & 2,2 & 1,29 & 2,27 & 5 & 0,16 & REJECT \\
\hline 34 & 5 & 6 & 8 & 7 & 9 & 1 & 2 & 3 & 4 & 441,414412 & 2,8646 & 2,2 & 1,26 & 2,11 & 5 & $-0,07$ & ACCEPT \\
\hline
\end{tabular}


International Journal of Mathematical, Engineering and Management Sciences

Vol. 3, No. 4, 365-380, 2018

https://dx.doi.org/10.33889/IJMEMS.2018.3.4-026

\begin{tabular}{|c|c|c|c|c|c|c|c|c|c|c|c|c|c|c|c|c|c|}
\hline 35 & 6 & 7 & 9 & 8 & 1 & 2 & 3 & 4 & 5 & 512,034645 & 3,3228 & 1,9 & 1,3 & 2,17 & 5 & 0,11 & REJECT \\
\hline 36 & 4 & 5 & 8 & 7 & 6 & 9 & 1 & 2 & 3 & 499,708009 & 3,2429 & 1,8 & 1,15 & 2,06 & 5 & 0,06 & REJECT \\
\hline 37 & 5 & 6 & 9 & 8 & 7 & 1 & 2 & 3 & 4 & 439,074191 & 2,8494 & 2 & 1,15 & 2 & 5 & $-0,17$ & ACCEPT \\
\hline 38 & 2 & 3 & 7 & 5 & 6 & 4 & 8 & 9 & 1 & 418,791946 & 2,7178 & 2,3 & 1,5 & 2,17 & 5 & 0,05 & ACCEPT \\
\hline 39 & 5 & 6 & 1 & 8 & 9 & 7 & 2 & 3 & 4 & 411,689657 & 2,6717 & 2,3 & 1,41 & 2,13 & 5 & 0,03 & ACCEPT \\
\hline 40 & 5 & 6 & 4 & 8 & 9 & 1 & 2 & 3 & 7 & 431,753855 & 2,8019 & 2,1 & 1,4 & 2,1 & 5 & 0 & ACCEPT \\
\hline 41 & 8 & 9 & 7 & 2 & 3 & 4 & 5 & 6 & 1 & 388,200048 & 2,5192 & 2,3 & 1,48 & 2,1 & 5 & $-0,14$ & ACCEPT \\
\hline 42 & 3 & 4 & 5 & 7 & 6 & 8 & 9 & 1 & 2 & 518,478499 & 3,3647 & 2,1 & 1,25 & 2,24 & 5 & 0,11 & REJECT \\
\hline 43 & 4 & 5 & 6 & 8 & 7 & 9 & 1 & 2 & 3 & 442,388382 & 2,8709 & 2,2 & 1,32 & 2,13 & 5 & 0,01 & ACCEPT \\
\hline 44 & 3 & 4 & 5 & 8 & 7 & 6 & 9 & 1 & 2 & 524,489782 & 3,4037 & 1,8 & 1,16 & 2,12 & 5 & 0,1 & REJECT \\
\hline 45 & 4 & 5 & 6 & 9 & 8 & 7 & 1 & 2 & 3 & 440,048161 & 2,8557 & 2 & 1,21 & 2,02 & 5 & $-0,06$ & ACCEPT \\
\hline 46 & 1 & 2 & 3 & 7 & 5 & 6 & 4 & 8 & 9 & 432,499487 & 2,8067 & 2,1 & 1,35 & 2,09 & 5 & $-0,02$ & ACCEPT \\
\hline 47 & 4 & 5 & 6 & 1 & 8 & 9 & 7 & 2 & 3 & 422,902309 & 2,7444 & 2,2 & 1,37 & 2,1 & 5 & $-0,24$ & ACCEPT \\
\hline 48 & 2 & 3 & 4 & 5 & 7 & 6 & 8 & 9 & 1 & 513,711793 & 3,3337 & 2,3 & 1,4 & 2,34 & 5 & 0,25 & REJECT \\
\hline 49 & 3 & 4 & 5 & 6 & 8 & 7 & 9 & 1 & 2 & 449,085486 & 2,9143 & 2,1 & 1,28 & 2,1 & 5 & 0,16 & ACCEPT \\
\hline 50 & 2 & 3 & 4 & 5 & 8 & 7 & 6 & 9 & 1 & 444,156065 & 2,8824 & 1,7 & 1,24 & 1,94 & 5 & $-0,05$ & ACCEPT \\
\hline 51 & 3 & 4 & 5 & 6 & 9 & 8 & 7 & 1 & 2 & 446,745265 & 2,8992 & 1,9 & 1,17 & 1,99 & 5 & $-0,08$ & REJECT \\
\hline 52 & 3 & 4 & 5 & 6 & 1 & 8 & 9 & 7 & 2 & 429,599413 & 2,7879 & 2,1 & 1,33 & 2,07 & 5 & $-0,09$ & ACCEPT \\
\hline 53 & 8 & 9 & 1 & 2 & 6 & 4 & 5 & 3 & 7 & 526,928713 & 3,4195 & 1,8 & 1,27 & 2,16 & 5 & 0,05 & REJECT \\
\hline 54 & 9 & 1 & 2 & 3 & 7 & 5 & 6 & 4 & 8 & 447,375294 & 2,9032 & 2,1 & 1,35 & 2,12 & 5 & $-0,09$ & ACCEPT \\
\hline 55 & 2 & 3 & 4 & 5 & 6 & 8 & 7 & 9 & 1 & 444,31878 & 2,8834 & 2,3 & 1,43 & 2,2 & 5 & 0,25 & ACCEPT \\
\hline 56 & 1 & 2 & 3 & 4 & 5 & 8 & 7 & 6 & 9 & 440,709322 & 2,86 & 1,9 & 1,1 & 1,95 & 5 & $-0,14$ & ACCEPT \\
\hline 57 & 2 & 3 & 4 & 5 & 6 & 9 & 8 & 7 & 1 & 441,978559 & 2,8682 & 2,1 & 1,32 & 2,1 & 5 & $-0,07$ & ACCEPT \\
\hline 58 & 2 & 3 & 4 & 5 & 6 & 1 & 8 & 9 & 7 & 451,378291 & 2,9292 & 2,1 & 1,48 & 2,17 & 5 & 0,14 & REJECT \\
\hline 59 & 7 & 8 & 9 & 1 & 2 & 6 & 4 & 5 & 3 & 482,247814 & 3,1295 & 1,8 & 1,15 & 2,03 & 5 & $-0,13$ & REJECT \\
\hline 60 & 8 & 9 & 1 & 2 & 3 & 7 & 5 & 6 & 4 & 471,498743 & 3,0598 & 2 & 1,4 & 2,15 & 5 & 0,04 & REJECT \\
\hline 61 & 1 & 2 & 3 & 4 & 5 & 6 & 8 & 7 & 9 & 458,026321 & 2,9724 & 2,1 & 1,28 & 2,12 & 5 & 0,04 & ACCEPT \\
\hline 62 & 7 & 8 & 9 & 1 & 2 & 3 & 5 & 4 & 6 & 491,963142 & 3,1926 & 1,8 & 1,25 & 2,08 & 5 & $-0,03$ & REJECT \\
\hline 6 & 8 & 9 & 1 & 2 & 3 & 4 & 6 & 5 & 7 & 459,79482 & 2,9838 & 2 & 1,34 & 2,11 & 5 & $-0,18$ & REJECT \\
\hline 64 & 9 & 1 & 2 & 3 & 4 & 5 & 7 & 6 & 8 & 542,295142 & 3,5192 & 2,1 & 1,25 & 2,29 & 5 & 0,31 & REJECT \\
\hline 65 & 1 & 2 & 3 & 4 & 5 & 6 & 9 & 8 & 7 & 432,997769 & 2,8099 & 1,9 & 1,23 & 1,98 & 5 & $-0,12$ & REJECT \\
\hline 66 & 7 & 8 & 9 & 1 & 2 & 3 & 6 & 5 & 4 & 440,687863 & 2,8598 & 2,1 & 1,33 & 2,1 & 5 & 0,1 & ACCEPT \\
\hline 67 & 9 & 1 & 2 & 3 & 4 & 5 & 8 & 7 & 6 & 449,855051 & 2,9193 & 1,9 & 1,18 & 2 & 5 & $-0,19$ & ACCEPT \\
\hline 68 & 9 & 1 & 2 & 3 & 4 & 5 & 6 & 8 & 7 & 492,37547 & 3,1953 & 2,1 & 1,28 & 2,19 & 5 & 2,19 & REJECT \\
\hline
\end{tabular}


International Journal of Mathematical, Engineering and Management Sciences

Vol. 3, No. 4, 365-380, 2018

https://dx.doi.org/10.33889/IJMEMS.2018.3.4-026

\section{Conclusions and Future Studies}

This chapter suggests a new multi objective simulated annealing for unequal area facility layout design problems. The relative function represented the normalized matric and evaluated with entropy weight functions. Facility Layout Problem (FLP) is defined as the problem of locating facilities in a limited area such that associated layout costs are minimized. Layout costs arise from various sources including material handling, time, and slack area.

The purpose of the study was to determine highest system performance design of the facility layout. It has been aimed to find most proper design with minimum cost that used of the alternative facility layout plans.

\section{References}

Ahmadi, A., Pishvaee, M. S., \& Jokar, M. R. A. (2017). A survey on multi-floor facility layout problems. Computers \& Industrial Engineering, 107, 158-170.

Al-Araidah, O., Krishnamurthy, A., \& Malmborg, C. J. (2006). A two-stage simulated annealing procedure for block layout problems. International Journal of Production Research, 44(20), 4417-4429.

Allahyari, M. Z., \& Azab, A. (2015, June). Improved Bi-level mathematical programming and heuristics for the cellular manufacturing facility layout problem. In ASME 2015 International Manufacturing Science and Engineering Conference (pp. V002T04A001, 10 pages). American Society of Mechanical Engineers.

Ariafar, S., \& Ismail, N. (2009). An improved algorithm for layout design in cellular manufacturing systems. Journal of Manufacturing Systems, 28(4), 132-139.

Armour, G. C., \& Buffa, E. S. (1963). A heuristic algorithm and simulation approach to relative location of facilities. Management Science, 9(2), 294-309.

Castillo, I., \& Sim, T. (2004). A spring-embedding approach for the facility layout problem. Journal of the Operational Research Society, 55(1), 73-81.

Chen, C. W., \& Sha, D. Y. (2005). Heuristic approach for solving the multi-objective facility layout problem. International Journal of Production Research, 43(21), 4493-4507.

Chiang, W. C., \& Kouvelis, P. (1996). An improved tabu search heuristic for solving facility layout design problems. International Journal of Production Research, 34(9), 2565-2585.

Chwif, L., Barretto, M. R. P., \& Moscato, L. A. (1998). A solution to the facility layout problem using simulated annealing. Computers in Industry, 36(1-2), 125-132.

Defersha, F. M., \& Hodiya, A. (2017). A mathematical model and a parallel multiple search path simulated annealing for an integrated distributed layout design and machine cell formation. Journal of Manufacturing Systems, 43(1), 195-212.

Drira, A., Pierreval, H., \& Hajri-Gabouj, S. (2007). Facility layout problems: A survey. Annual Reviews in Control, 31(2), 255-267.

Eglese, R. W. (1990). Simulated annealing: a tool for operational research. European Journal of Operational Research, 46(3), 271-281.

Fortenberry, J. C., \& Cox, J. F. (1985). Multiple criteria approach to the facilities layout problem. International Journal of Production Research, 23(4), 773-782. 
International Journal of Mathematical, Engineering and Management Sciences

Vol. 3, No. 4, 365-380, 2018

https://dx.doi.org/10.33889/IJMEMS.2018.3.4-026

Heragu, S. S., \& Kusiak, A. (1991). Efficient models for the facility layout problem. European Journal of Operational Research, 53(1), 1-13.

Jankovits, I., Luo, C., Anjos, M. F., \& Vannelli, A. (2011). A convex optimisation framework for the unequal-areas facility layout problem. European Journal of Operational Research, 214(2), 199-215.

Khilwani, N., Shankar, R., \& Tiwari, M. K. (2008). Facility layout problem: an approach based on a group decision-making system and psychoclonal algorithm. International Journal of Production Research, 46(4), 895-927.

Kirkpatrick, S., Gelatt, C. D., \& Vecchi, M. P. (1983). Optimization by simulated annealing. Science, 220(4598), 671-680.

Lee, R., \& Moore, J. M. (1967) CORELAP computerized relationship layout planning. The Journal of Industrial Engineering, 18, 195-200.

Liggett, R. S. (2000). Automated facilities layout: past, present and future, Automation in Construction, 9 , 197-215.

McKendall Jr, A. R., Shang, J., \& Kuppusamy, S. (2006). Simulated annealing heuristics for the dynamic facility layout problem. Computers \& Operations Research, 33(8), 2431-2444.

Meller, R. D., \& Gau, K. Y. (1996). The facility layout problem: recent and emerging trends and perspectives. Journal of Manufacturing Systems, 15(5), 351-366.

Rardin, R. L. (2000). Optimization in Operations Research, Prentive Hall, April.

Rosenblatt, M. J. (1986). The dynamics of plant layout. Management Science, 32(1), 76-86.

Saraswat, A., Venkatadri, U., \& Castillo, I. (2015). A framework for multi-objective facility layout design. Computers \& Industrial Engineering, 90, 167-176.

Seehof, J. M., \& Evans, W. O. (1967). Automated layout design program. Journal of Industrial Engineering, 18(12), 690-695.

Shayan, E., \& Chittilappilly, A. (2004). Genetic algorithm for facilities layout problems based on slicing tree structure. International Journal of Production Research, 42(19), 4055-4067.

Singh, S. P., \& Sharma, R. R. K. (2008). Two-level modified simulated annealing based approach for solving facility layout problem. International Journal of Production Research, 46(13), 3563-3582.

Singh, S. P., \& Singh, V. K. (2010). An improved heuristic approach for multi-objective facility layout problem. International Journal of Production Research, 48(4), 1171-1194.

Şahin, R., \& Türkbey, O. (2009). A simulated annealing algorithm to find approximate pareto optimal solutions for the multi-objective facility layout problem. The International Journal of Advanced Manufacturing Technology, 41(9-10), 1003-1018.

Taghavi, A., \& Murat, A. (2011). A heuristic procedure for the integrated facility layout design and flow assignment problem. Computers \& Industrial Engineering, 61(1), 55-63.

Tompkins, J. A., \& Reed, J. R. (1976). An applied model fort he facilities design problem. International Journal of Production Research, 14, 583-595.

Torkul, O., Sencer, S., Cesur, M. R., \& Demirkir, M. S. (2013). Evaluation of the facility layout design parameters using fuzzy decision making. CIE43 Proceedings, 16-18 October, The University of Hong Kong, 1-12.

Yang, T., \& Kuo, C. (2003). A hierarchical AHP/DEA methodology for the facilities layout design problem. European Journal of Operational Research, 147(1), 128-136. 